\title{
Ultrasound Imaging of Gestational Trophoblastic Disease
}

Wayne Tie, Kathrene Tajnert, Sanja Kupesic Plavsic

\begin{abstract}
Gestational trophoblastic diseases (GTD) comprise several entities which all arise due to abnormal growth of trophoblastic cells of the placenta. These disease processes range from benign to malignant. GTD are classified as complete hydatidiform mole, partial mole, invasive mole and choriocarcinoma. The imaging of choice for detecting trophoblastic disease is B-mode ultrasonography and color Doppler. When ultrasonography corresponds with the classic clinical presentation, accurate diagnosis is possible in a majority of cases of GTD. This article goes through several cases of GTD. Each case will demonstrate and review the principles of ultrasound diagnosis of different forms of GTD and apply it to the presented case studies. With early and accurate diagnosis with the help of ultrasonography, the cure rate for GTD is high.
\end{abstract}

Keywords: Gestational trophoblastic disease, Molar pregnancy, Complete hydatidiform mole, Partial mole, Invasive mole, Choriocarcinoma, B-mode ultrasound, Doppler ultrasound.

How to cite this article: Tie W, Tajnert K, Plavsic SK. Ultrasound Imaging of Gestational Trophoblastic Disease. Donald School J Ultrasound Obstet Gynecol 2013;7(1):105-112.

\section{Source of support $\mathrm{Nil}$}

Conflict of interest: None declared

\section{INTRODUCTION}

Gestational trophoblastic disease (GTD) represents the set of diseases associated with abnormal development of placental tissue. These diseases include hydatidiform moles, invasive moles and trophoblastic neoplasms. The incidence rate of hydatidiform mole in the United States is approximately $0.5-1 / 1,000$ pregnancies and the incidence rate is increased in women of $A$ sian descent. ${ }^{1,2} \mathrm{H}$ ydatidiform mole transformation into trophoblastic neoplasia occurs in about 16 to $20 \%$ of patients with complete mole and $0.5 \%$ of patients with partial mole. ${ }^{3,4} \mathrm{~A}$ dditionally, risk factors for GTD include increased maternal age, previous molar pregnancy, previous abortions and smoking. ${ }^{5}$

Typically GTD presents clinically in women as abnormal first trimester vaginal bleeding and enlarged uterus. In such cases, other differential diagnoses must be ruled out. $V$ aginal bleeding may arise from obstetric causes such as ectopic pregnancy or spontaneous abortion as well as of gynecologic etiology in cases of uterine fibroids or polyps. Ultrasound imaging has become standard protocol in aiding in diagnosis of vaginal bleeding and suspected GTD. Standard B-mode ultrasound is useful in detecting the presence of fetal pole and abnormal uterine masses, while color and pulsed Doppler sonography is effective in assessing blood flow through the uterine vasculature. These ultrasound modalities in combination provide a cost-effective and noninvasive screening tool which can then be followed up with tissue histology and computed tomography/magnetic resonance imaging (CT/M RI) imaging. A the same time, classic pelvic sonography has its limitations in producing a threedimensional (3D) view of the uterus, the physical maneuverability of the transvaginal probe, and its decreased effectiveness in obese patients. ${ }^{6}$

In all cases of vaginal bleeding and uterine enlargement, pregnancy test is the paramount first step in diagnosis. N egative beta-hCG can usually exclude most cases of GTD, while significantly elevated levels are nearly pathognomonic for presence of GTD, although exceptions to the rule require clinical judgment on the need for additional studies. In the presence of positive beta-hCG findings, history and physical can provide a guide for further evaluation. A bnormal vaginal bleeding in pregnancy, nausea and vomiting, urinary symptoms and pelvic pain require additional evaluation. Similarly, significant physical exam findings include enlarged uterus, blood on speculum exam, or presence of adnexal masses. If there is suspicion for GTD, pelvic ultrasound is the most appropriate next step for further assessment.

\section{CASE REPORTS}

\section{Case 1}

A 25-year-old G 1 P0 presents with painless vaginal bleeding. Her last menstrual period was 14 weeks ago. On physical exam, her temperature is $36.8^{\circ} \mathrm{C}$, pulse 90 beats per minute, blood pressure 180/145. Blood pressure is stabilized and pelvic exam shows a small amount of blood in the vagina and an enlarged nontender uterus with normal adnexa. Doppler ultrasound reveals no fetal heart tones. Her betahCG was 290,000 mlU/ml (normal: 13,300-254,000 mlU/ $\mathrm{ml}$ ). 3D ultrasound reveals fetal pole with absent heart activity and hydropic changes of the placenta (Fig. 1). Evacuation of products of conception was performed and the specimen was sent for cytogenetic analysis.

\section{Case 2}

An 18-year-old G2 P1 previously heal thy J apanese woman at 16 weeks gestation based on $L M P$, presented to the ED with painless vaginal bleeding. The patient states she has been having worsening nausea and vomiting for the last 


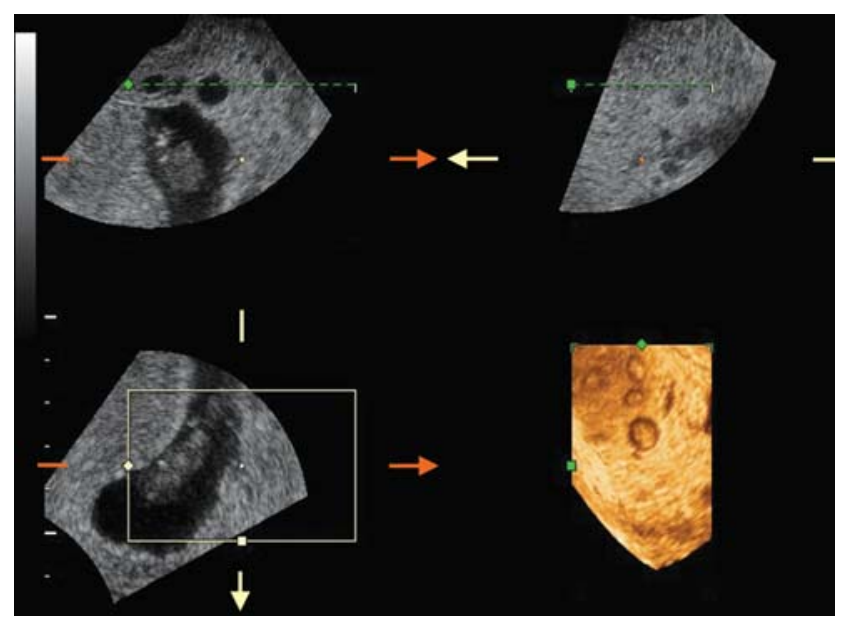

Fig. 1: 3D ultrasound image of a patient presenting with painless vaginal bleeding. Note: Hydropic changes of the placenta and fetal pole with absent cardiac activity (Courtesy: Guillermo Azumendi, MD)

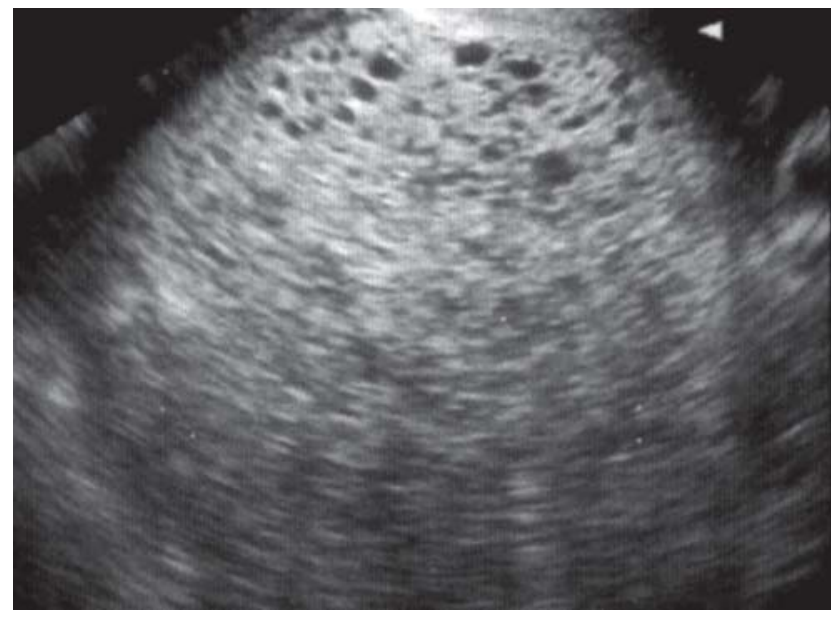

Fig. 2: Transvaginal ultrasound demonstrating snowstorm appearance of the uterus

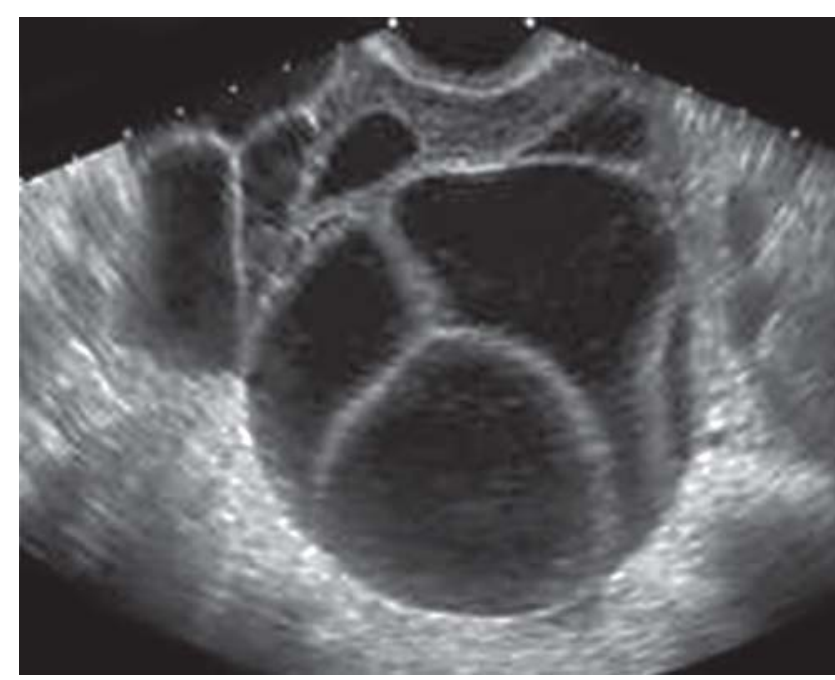

Fig. 3: Transvaginal ultrasound demonstrating bilateral theca luteinic cysts of the ovaries

few weeks and now is unable keep anything down. She al so states she has had chest palpitations, which did not occur previous to her pregnancy. On physical exam, her temperature is $98.6^{\circ} \mathrm{F}\left(37.0^{\circ} \mathrm{C}\right)$, heart rate is 122 beats per minute, and blood pressure is 145/93. A bdominal and pelvic examination confirms a 20-week sized uterus with blood in the vaginal vault. Quantitative beta-hCG was 147,000 $\mathrm{mlU} / \mathrm{ml}$. Fetal Doppler tones are not auscultated. Ultrasound assessment of the uterus (Fig. 2) demonstrates multipleinternal echoes consistent with a 'snowstorm' appearance in the uterus. No fetal pole was visualized. U Itrasound assessment of the ovaries demonstrated theca lutein cysts bilaterally (Fig. 3). The patient was transfused for anemia, and vacuum extraction was performed. Genetic analysis was performed and revealed 46XX karyotype. The patient was monitored for bleeding, and postprocedural serial beta-hCG was performed to rule out the development of malignant disease.

\section{Case 3}

A 42-year-old G 4 P3 presented at 15 w eeks gestation with abnormal painless vaginal bleeding which started on the previous day. She states she is also feeling weak and nauseous and comments that this never occurred with her previous pregnancy. On exam, temperature is $97.9^{\circ} \mathrm{F}$, heart rate is 98 beats per minute, and blood pressure is 159/90. L aboratory studies showed quantitative beta-hCG was $182,000 \mathrm{mlU} / \mathrm{ml}$. On abdominal examination the fundus was at the umbilicus, inconsistent with gestational age. The thyroid was normal on palpation. The lung and heart examinations are unremarkable. B-mode ultrasound demonstrated snowstorm appearance of the uterus. $N$ o fetal pole was visualized. Color D oppler demonstrated prominent blood flow signals within the myometrial portion of the uterus (Fig. 4). Color D oppler studies detected reduction of vascular impedance in the uterine arteries (Fig. 5). G enetic analysis revealed 46XY karyotype.

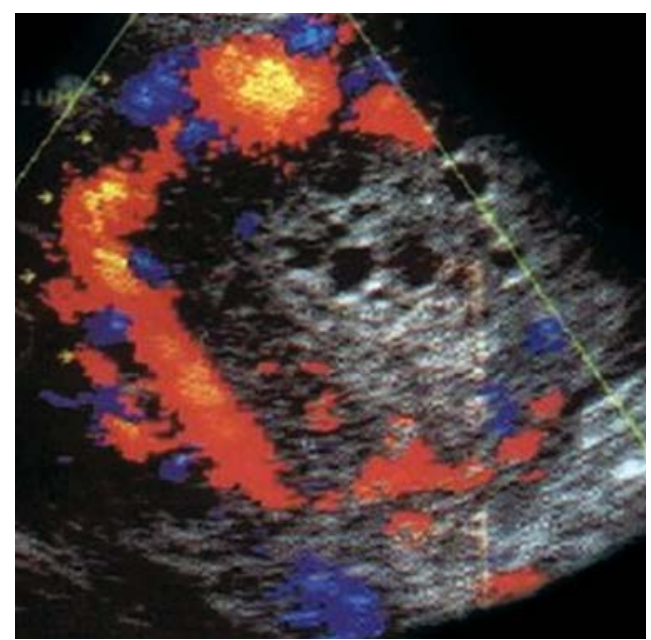

Fig. 4: Transvaginal color Doppler scan of the uterine cavity with 'snowstorm' appearance (Note: prominent blood flow signals within the myometrial portion of the uterus) 


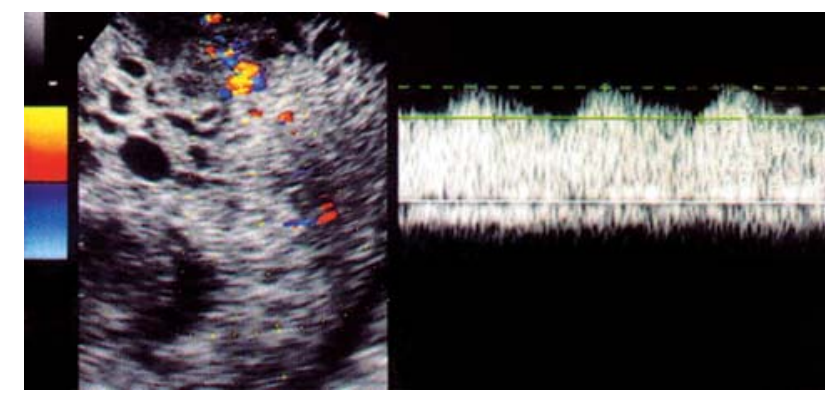

Fig. 5: Pulsed Doppler waveform analysis demonstrates reduce vascular impedance of the uterine artery $(\mathrm{RI} 0.26)$

\section{Case 4}

A 22-year-old G1P1 presents with irregular vaginal bleeding. She reports feeling progressively more fatigued since the delivery of her child 8 months ago. Recently, she has had two episodes of hemoptysis. On physical exam, she has lower and right upper quadrant abdominal tenderness and her skin appears slightly jaundiced. H er vital signs are temperature $37.0^{\circ}$, pulse 80 beats per minute, blood pressure $130 / 80$ and respiratory rate 16 breaths per minute. Pelvic exam reveals a normal appearing cervix, enlarged uterus and no adnexal masses or tenderness. Serum measurement shows beta-hCG level of $180,000 \mathrm{mIU} / \mathrm{ml}$. Pelvic ultrasound reveals heterogeneous uterine mass. Color and power Doppler demonstrates signs of neovascularization (Figs 6 and 7). Waveform analysis shows low vascular impedance blood flow signals (RI 0.29) obtained from bright color-coded areas within the uterus (Fig. 8). Chest and abdominal $X$-ray reveal multiple densities in the patient's lung and liver.

\section{CASE DISCUSSION}

\section{Case 1: Partial Hydatidiform Mole}

Genetic analysis of the evacuated products of conception demonstrates 69X XX karyotype. Painless vaginal bleeding

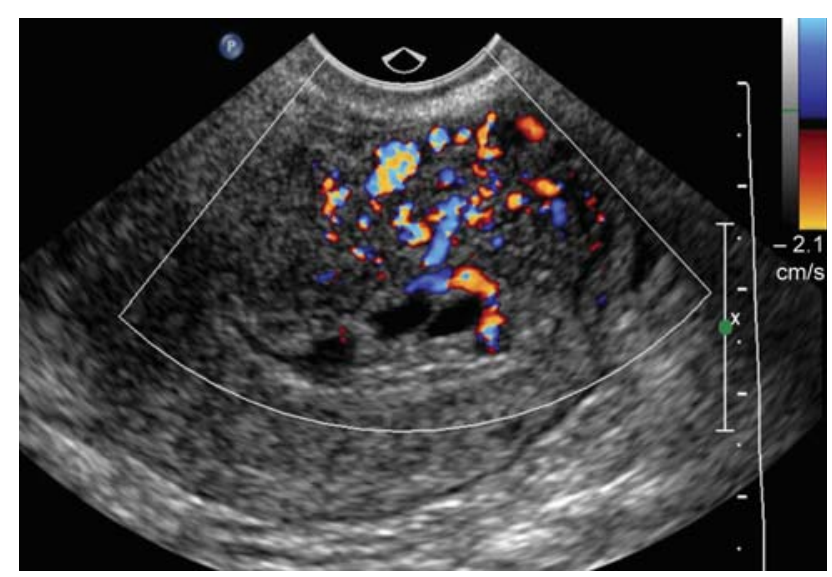

Fig. 6: Transvaginal color Doppler scan of a patient presenting with irregular vaginal bleeding, hemoptysis and jaundice

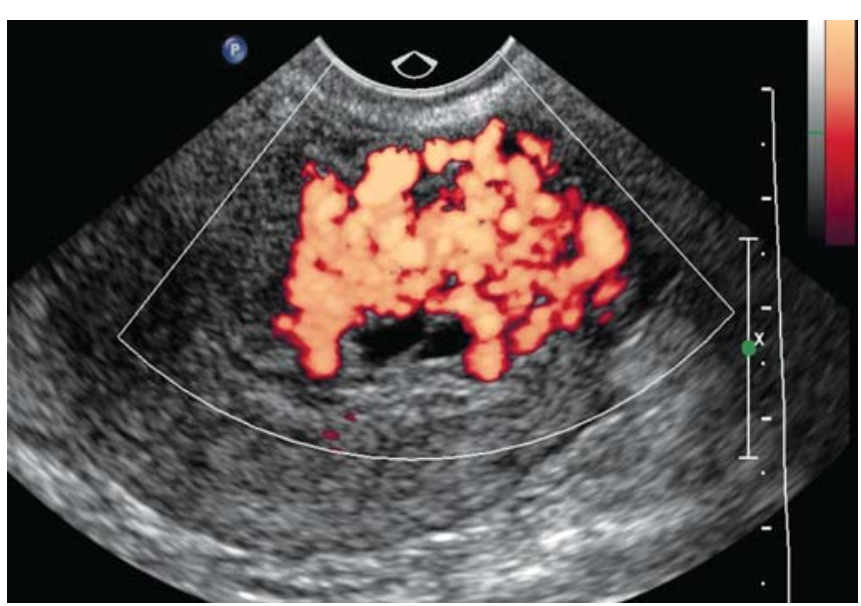

Fig. 7: Transvaginal power Doppler scan of the same patient. Note: The numerous randomly dispersed vessels typical for neovascularization

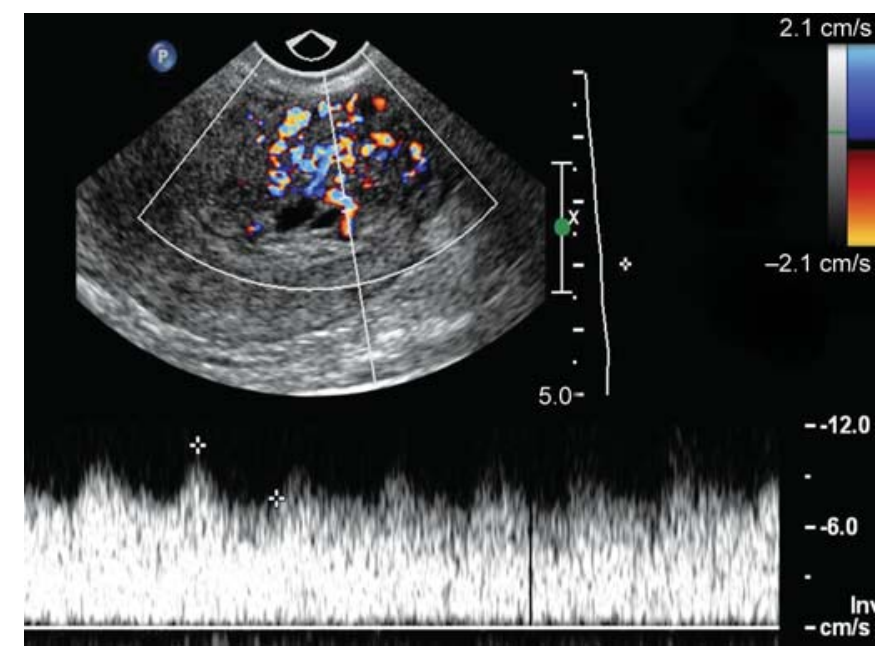

Fig. 8: Transvaginal color Doppler scan of the same patient. Low vascular resistance $(R I=0.29)$ is obtained from bright color-coded zones within the uterus

with products of conception on ultrasound and $69 \mathrm{XXX}$ karyotype is highly suggestive of partial molar pregnancy. A partial mole is derived from the fertilization of a single ovum by two separate sperms, producing a triploid trophoblast with one maternal and two paternal sets of chromosomes. ${ }^{7}$ The end result is a nonviable pregnancy with fetal tissue detectable on sonography. Unlike complete moles, partial moles have a lesser tendency to transform into a gestational trophoblastic neoplasm. ${ }^{8}$

This classic presentation of partial molar pregnancy may range from asymptomatic enlarged uterus to painless vaginal bleeding in the first trimester, very similar signs as incomplete or missed abortion. ${ }^{9} \mathrm{~A}$ lthough vital signs are usually stable, patients may present with hypertension due to the elevated beta-hCG levels and its structural similarity to thyroid stimulating hormone (TSH) ${ }^{10}$

The patient in this case is a 25-year-old G1P0 at 14 weeks gestation with vaginal bleeding, hypertension and abnormal pelvic exam. As with both complete and partial 
molar pregnancies, pelvic ultrasound evaluation and betahCG measurement are the investigations of choice for diagnosis. These are important in ruling out incorrect dating and to look for viable intrauterine pregnancy. B-mode ultrasound reveals enlarged area of villous tissue along with presence of fetal pole. Thickened placenta relative to the size of the fetus and cystic spaces within the placenta were suggestive of partial mole. Color Doppler ultrasound shows zones of high vascularization around the trophoblast signifying enlargement of spiral arteries. However, Doppler ultrasound alone cannot be used to differentiate between complete and partial hydatidiform mole. ${ }^{11}$ The combination of B-mode with the color Doppler ultrasound facilitates detection of fetal heart activity and fetal parts, which is important in ruling out differential diagnoses. The obvious benefit of $3 \mathrm{D}$ ultrasound imaging in this setting is in its improved spatial orientation and demonstration of multiplanar views, as shown in Figure 1. It is important to note that partial moles may often be missed on first trimester sonogram as miscarriage; therefore, histologic exam is still necessary to correctly diagnose the presence of GTD. ${ }^{12}$

In this case, the patient will receive dilatation and curettage procedure and RhoGAM after diagnosis if she is Rh-negative. She will be monitored for further bleeding, and postprocedural serial beta-hCG measurements should be followed for up to 2 years. ${ }^{9}$ Early sonogram is also recommended for subsequent pregnancies due to this patient's increased risk of recurrent molar pregnancy. ${ }^{13}$

\section{Case 2: Complete Hydatidiform Mole}

The patient has a classic presentation for a molar pregnancy. Typically, the most affected patients are young ( $<20$ years) and older (>40 years) reproductive ages, and in A sian, $\mathrm{L}$ atino, and Filipino populations. ${ }^{14,15} \mathrm{In} \mathrm{J}$ apan, the incidence of molar pregnancy is 2.0 per 1,000 pregnancies, which is approximately three times higher than the incidence in Europe or N orth A merica. ${ }^{15} \mathrm{~V}$ aginal bleeding in the first trimester of pregnancy is the most common presenting symptom in complete molar pregnancy, although passage of hydropic villi can occur. ${ }^{16}$ Other clinical signs and symptoms include uterus too large for dates, which can be seen in approximately $25 \%$ of moles, pain from benign thecalutein cysts $(20 \%)$, hyperemesis $(10 \%)$, hyperthyroidism (5\%), and hypertension due to early pre-eclampsia (5\%). ${ }^{17}$ There is a detectable beta-hCG in molar pregnancies, although notably higher than the values observed in normal pregnancy. The presence of these features in the first half of pregnancy and a beta-hC G level $>100,000$, can make the clinical suspicion of complete molar pregnancy high. ${ }^{18}$ In addition, the tachycardia the patient in this case experiences is most likely attributed to hyperthyroidism. The effect on the thyroid is explained by the similarities between the structures of beta-hCG and TSH. The molecular structure of hCG is composed of $\alpha$ and $\beta$ subunits and it is the al phasubunit of beta-hCG that is identical to TSH, LH and FSH. The potency of beta-hCG for TSH receptors is significantly less than TSH and therefore, extremely high levels of betahCG are required for an effect on thyroid function to be seen. ${ }^{10}$

In order to establish the diagnosis, ultrasound is the imaging of choice. A complete hydatidiform mole has a characteristic 'snowstorm' appearance on ultrasound. This is caused by the presence of multiple hydropic villi. A complete hydatidiform mole is characterized by generalized swelling of the villous tissue, trophoblastic hyperplasia and with no fetal tissue present. ${ }^{19}$ In addition to the ultrasound examination of the uterus the ovaries should be studied as well. It is of high importance due to the fact that approximately $20 \%$ of patients with a complete mole will have theca lutein cysts of the ovaries present. ${ }^{11}$ Theca lutein cysts are related to hCG hyperstimulation of the ovaries. ${ }^{16}$

Complete hydatidiform moles are diploid and completely derived from the paternal genome with a chromosomal constitution of $46 \mathrm{XX}$. This occurs in the majority of cases (82-86\%). ${ }^{11}$ In those cases the complete mole arises from haploid sperm (monospermic) fertilization of an anuclear ovum and then reduplicates its own chromosomes, resulting in the 46XX karyotype. In less than $10 \%$ of cases, dispermic fertilization occurs and the complete mole results in either a $46 X X$ or a $46 X Y$ karyotype. ${ }^{20}$

A pproximately, $8 \%$ of patients with complete mole will develop a malignant tumor after evacuation. ${ }^{8}$ Therefore, serial values of beta-hCG should be obtained after evacuation. The Cancer Committee of the International Federation of Gynecologists and Obstetricians (FIGO) has established the following guidelines for the diagnosis of postmolar gestational trophoblastic neoplasia (GTN):21

1. Four values or more of beta-hCG plateaued over at least 3 weeks

2. An increase in $\mathrm{hCG}$ of $10 \%$ or greater for 3 or more values over at least 2 weeks

3. The histologic diagnosis of choriocarcinoma

4. Persistence of hCG 6 months after molar evacuation.

\section{Case 3: Invasive Mole}

In this case, the patient's clinical presentation of advanced maternal age, vaginal bleeding, hyperemesis gravidarum, signs of pre-eclampsia (in early pregnancy) and enlarged uterus demonstrate a classic presentation for a complete molar pregnancy. The presence of these features in the first half of pregnancy and a beta-hCG level $>100,000 \mathrm{mIU} / \mathrm{ml}$ can make the clinical suspicion of molar pregnancy high. ${ }^{18}$ 
Ultrasound is the imaging of choice when molar pregnancy is suggested. In this case, color Doppler demonstrated prominent blood flow signals within the myometrial portion of the uterus. This finding is pathognomonic for invasive mole. Secondary to myometrial invasion, color Doppler studies detected reduction of vascular impedance in the uterine arteries. In many cases B-mode real-time scan is not sufficient for the diagnosis of invasive mole and estimation of the myometrial invasion. Instead, by using transvaginal color Doppler, trophoblastic invasion into myometrial tissue is recognized. It can be visualized as prominent color-coded zones in the myometrium and high velocity and low impedance blood flow pattern displayed by pulsed Doppler waveform analysis. ${ }^{11}$

A $n$ invasive hydatidiform mole is a form of GTN that occurs due to abnormal proliferation of placental trophoblast. They are characterized by the presence of edematous chorionic villi with trophoblastic proliferation that invades into the myometrium of the uterus or to adjacent structures. ${ }^{22}$ I nvasive mole is unlike choriocarcinoma which is without the presence of chorionic villi.

A n invasive mole most commonly occurs after the evacuation of GTD. Although both complete and partial moles have the potential to become invasive, it is more common following complete moles. ${ }^{23}$ The incidence of an invasive hydatidiform mole occurring after evacuation of a complete hydatidiform mole is 10 to $15 \% .{ }^{11}$ Invasive moles are rarely metastatic.

$M$ anagement of an invasive mole includes treatment with chemotherapy as well as continued monitoring of beta-hCG . Patients with GTN should be followed with weekly quantitative beta-hCG levels until normal for 3 consecutive weeks, then monthly for 12 months. ${ }^{24}$ Dilation and curettage is not recommended due to the risk of uterine perforation. ${ }^{22}$

\section{Case 4: Choriocarcinoma}

Choriocarcinoma is a malignant neoplasm arising from gestational trophoblastic tissue. It is a rare disease occurring in about one in 50,000 deliveries. ${ }^{4}$ It can present as painless vaginal bleeding after diagnosis of molar pregnancy or as abnormal bleeding several months following delivery, as seen in this patient.

Histologically, choriocarcinomas are beta-hCG producing epithelial tumors with high vascularity and abnormal cell proliferation characteristic of malignant neoplasms. ${ }^{7}$ For this reason, beta-hCG levels and Doppler ultrasound are ideal modalities in cases of suspected choriocarcinoma. Pelvic exam in this 22-year-old patient reveals enlarged uterus. In isolated findings of el evated betahCG and enlarged uterus, incorrect dating, hydatidiform mole and choriocarcinoma are all possible diagnoses. Hence, $\mathrm{B}$-mode ultrasound is used first to detect the presence or absence of intrauterine pregnancy and rule out uterine and/ or adnexal masses. In cases of high suspicion of GTD, color Doppler ultrasound is the modality of choice for assessment of angiogenesis and neovascularization. ${ }^{7} \mathrm{~B}$-mode ultrasound shows a heterogeneous uterine mass, and color/power and pulsed Doppler ultrasound (Figs 6 to 8 ) demonstrates signs of neovascularization, characterized by high velocity and low impedance blood flow. Furthermore, the neoplastic vessels of choriocarcinomas have decreased vascular resistance in comparison to the vessels seen in hydatidiform moles. $^{11}$

In this patient, the beta-hCG and ultrasound findings are indicative of choriocarcinoma in the uterus. Furthermore, this woman presents with dyspnea, hemoptysis, abdominal pain, as well as jaundice. These manifestations are attributed to the hematogenous spread of the tumor to the lung and liver due to the high metastatic potential of choriocarcinomas, and warrant further investigations. ${ }^{25}$ Chest $X$-ray and abdominal CT are the next appropriate steps in diagnosis due to her symptoms of hemoptysis and jaundice. ${ }^{26} \mathrm{Head} C \mathrm{CT}$ may be beneficial had she presented with neurologic symptoms in addition to her positive $\mathrm{X}$-ray findings. ${ }^{27}$

This 22-year-old patient was eventually treated with hysterectomy, chemotherapy (etoposide, methotrexate and actinomycin D), and radiation therapy. Normally, follow-up management of choriocarcinoma consists of serial beta-hCG level monitoring over the next 3 years and patient should be placed on contraceptives for at least 1 year. ${ }^{28}$ Color Doppler has also been shown to be an effective tool in predicting the resolution or persistence of choriocarcinoma post-treatment. ${ }^{29,30} \mathrm{U}$ nfortunately, the patient in this case deceased 8 months after diagnosis.

\section{REFERENCES}

1. A trash HK, Hogue CJ, Grimes DA. Epidemiology of hydatidiform mole during early gestation. A m J Obstet Gynecol 1986;154(4):906-09.

2. Bracken M B. Incidence and aetiology of hydatidiform mole: A n epidemiologic review. Br J Obstet Gynaecol 1987;94(12): 1123-35.

3. Fu J, Fang F, Xie L, et al. Prophylactic chemotherapy for hydatidiform mole to prevent gestational trophoblastic neoplasia. Cochrane Database Syst Rev 2012;10:CD 007289.

4. Ngan S, Seckl MJ. Gestational trophoblastic neoplasia management: A n update. Curr Opin Oncol 2007;19(5):386-91.

5. F reedman RS, Tortolero-L una G, Pandey DK, et al. G estational trophoblastic disease. Obset Gynecol Clin North A m 1996;23(2):545-71.

6. B ega G, L ev-T oaff A S, et al. Three-dimensional ultrasonography in gynecology: Technical aspects and clinical applications. J Ultrasound M ed 2003;22(11):1249-69. 
7. Seckl MJ, Sebire NJ, Berkowitz RS. Gestational trophoblastic disease. Lancet 2010;376(9742):717-29.

8. Martonffy AI, Rindfleisch K, L ozeau AM, Potter B. First trimester complications. Prim Care 2012;39(1):71-82.

9. Sasaki S. Clinical presentation and management of molar pregnancy. Best Prac Res Clin Obstet Gynaecol 2003;17(6): 885-92.

10. Walkington L, W ebster J, Hancock BW, Everard J, Coleman RE. Hyperthyroidism and human chorionic gonadotrophin production in gestational trophoblastic disease. $\mathrm{Br} J$ Cancer 2011;104(11):1665-69.

11. K upesic Plavsic S, K urjak A, B aston K. G estational trophoblastic disease. In: Kupesic Plavsic S (Ed). Color Doppler, 3D and 4D ultrasound in gynecology, infertility and obstetrics. L ondon, New Delhi, Panama City, St. Louis: J aypee Publishers 2011; 243-51.

12. Sebire NJ, Rees H, Paradinas F, Seckl M, Newlands E. The diagnostic implications of routine ultrasound examination in histologically confirmed early molar pregnancies. Ultrasound Obstet Gynecol 2001;18(6):662-65.

13. Berkowitz RS, Goldstein DP. Chorionic tumors. N Engl J M ed 1996;335(23):1740-48.

14. A Itman AD, B entley B, M urray S, B entley JR. M aternal agerelated rates of gestational trophoblastic disease. 0 bstet $G$ ynecol 2008 A ug;112(2 Pt 1):244-50.

15. Smith $\mathrm{HO}$. Gestational trophoblastic disease epidemiology and trends. Clin Obstet Gynecol 2003;46:541-56.

16. Soper JT. Gestational trophoblastic disease. Obstet Gynecol 2006 Jul;108(1):176-87.

17. Cavaliere A, Ermito S, Dinatale A, Pedata R. M anagement of molar pregnancy. J Prenat M ed 2009 Jan;3(1):15-17.

18. Cole LA . N ew discoveries on the biology and detection of human chorionic gonadotropin. Reprod Biol Endocrinol 2009;7:8.

19. Szulman AE, Surti $U$. The syndromes of hydatidiform mole. II. Morphology evolution of the complete and partial mole. A m J Obstet Gynecol 1978;132:22-27.

20. Chiang S, Fazlollahi L, N guyen A, B etensky RA, Roberts DJ, Iafrate AJ. Diagnosis of hydatidiform moles by polymorphic deletion probe fluorescence in situ hybridization. J M ol Diagn 2011 J uly;13(4):406-15.

21. Goldstein DP, B erkowitz RS. Current management of gestational trophoblastic neoplasia. Hematol Oncol Clin North A m 2012 Feb;26(1):111-31.

22. Soper JT, et al. Diagnosis and treatment of genstational trophoblastic disease: A CO G Practice B ull letin N 0.53. Gyencol Oncol 2004;93(3):575-85.
23. Jauniaux E. Ultrasound diagnosis and follow-up of gestational trophoblastic disease. Ultrasound Obstet Gynecol 1998;11: 367-77.

24. M ay T, Goldstein DP, B erkowitz RS. Current chemotherapeutic management of patients with gestational trophoblastic neoplasia. Chemother Res Pract 2011;2011:806256.

25. Shih, IeM. Gestational trophoblastic neoplasia- pathogenesis and potential therapeutic targets. Lancet Oncol 2007;8(7): 642-50.

26. Berkowitz RS, Goldstein DP. Current advances in the management of gestational trophoblastic disease. Gynecol Oncol 2013 J an;128(1):3-5.

27. Newlands ES, Holden L, Seckl MJ, M cN eish I, Strickland S, Rustin GJ. M anagement of brain metastases in patients with high-risk gestational trophoblastic tumors. J Reprod Med 2002;47(6):465-71.

28. Tse KY , N gan HY . Gestational trophoblastic disease. B est Pract Res Clin Obstet Gynaecol 2012;26(3):357-70.

29. Zanetta G, Lisoni A, Colombo M, et al. Detection of abnormal intrauterine vascularization by color Doppler imaging: $A$ possible additional aid for the follow-up of patients with gestational trophoblastic tumors. Ultrasound Obstet Gynecol 1996;7(1):32-37.

30. M aeda $K$, Kurjak A, V arga G, Honemeyer U. Trophoblastic diseases. Kurjak A, Chervenak F (Eds). Donald school textbook of ultrasound in obstetrics and gynecology. L ondon, N ew D el hi, Panama City, St. L ouis: J aypee Publishers 2011;157-74.

\section{ABOUT THE AUTHORS Wayne Tie}

Student Physician, Department of M edical Education, Paul L Foster School of Medicine, Texas Tech U niversity, EI Paso, Texas, USA

\section{Kathrene Tajnert}

Student Physician, Department of M edical Education, Paul L Foster School of Medicine, Texas Tech U niversity, EI Paso, Texas, USA

\section{Sanja Kupesic Plavsic (Corresponding Author)}

Professor of Obstetrics/Gynecology and Radiology, Department of Obstetrics and Gynecology, Paul L Foster School of M edicine, Texas Tech University, 4800 Alberta A ve, EI Paso, Texas, USA, Phone: +1 (915) 783-1700, e-mail: sanja.kupesic@ttuhsc.edu 
1. A 32-year-old G 2 P 1 at 14 weeks gestation, presented with vaginal bleeding, hyperemesis gravidum, and pre-eclampsia. Beta-hC G is 140,500 $\mathrm{mIU} / \mathrm{ml}$. Ultrasound showed a snowstorm appearance of the uterus. She underwent dilation and curettage due to molar pregnancy. The pathology report confirmed a complete molar pregnancy with karyotype 46XX. Which of the following is true of a complete mole?

A. Fetus or fetal parts are typically present

B. There is lower risk of developing persistent (postmolar) gestational trophoblastic disease compared to incomplete mole

C. Complete moles are viable pregnancies

D. Complete moles most commonly result from the fertilization of an empty ovum

2. A 28-year-old G 4 P3 at 15 weeks gestation, presents with vaginal bleeding. On exam, her uterus is $\mathbf{2 0}$ weeks size. Beta-hCG is $191,000 \mathrm{mlU} / \mathrm{ml}$. Ultrasound revealed a snowstorm appearance, suggestive of a molar pregnancy. What is the recommended treatment for this patient?
A. Expectant management
B. Methotrexate
C. Induction of labor with oxytocin
D. Suction curettage

3. A 35-year-old G 3 P2 of A sian origin, undergoes dilation and curettage due to a confirmed complete molar pregnancy. What is the chromosomal origin of the complete mole?
A. Diploid; derived from paternal genome with a chromosomal constitution of $46 \mathrm{XX}$
$B$. Diploid; derived from maternal genome with a chromosomal constitution of $46 \mathrm{XX}$
C. Haploid; derived from paternal genome with a chromosomal constitution of $69 \times X X$
D. Haploid; derived from maternal genome with a chromosomal constitution of $46 \mathrm{XX}$

4. A 39-year-old G 2 P1 with recent evacuation of completemolecontinues to have elevated beta-hC G of $120,000 \mathrm{mIU} / \mathrm{ml}$. Using transvaginal color Doppler, it reveals trophoblastic invasion into myometrial tissue. Tissue sampling shows the presence of edematous chorionic villi with trophoblastic proliferation that invades into the myometrium of the uterus. W hat is the most likely diagnosis?
A. Partial mole
B. Invasive mole

\section{Choriocarcinoma \\ D. Ectopic pregnancy}

5. A 20-year-old G 2 P1 presents at 15 weeks gestation with abnormal painless vaginal bleeding. She states she is also feeling weak and nauseous. On exam, temperature is $97.1^{\circ} \mathrm{F}$, heart rate is 98 beats per minute, and blood pressure is $149 / 90$. L ab studies show quantitative beta-hC G as $182,000 \mathrm{mI} \mathrm{U} / \mathrm{ml}$. On abdominal examination the fundus was at the umbilicus, inconsistent with gestational age. Bmode ultrasound reveals snowstorm appearance of the uterus and no fetal pole was seen. Color Doppler demonstrated prominent blood flow signals within the myometrial portion of the uterus. What is best treatment option for this patient's nonmetastatic invasive mole?
A. Hysterectomy
B. Low-risk GTN are treated with single-agent chemotherapy, methotrexate
C. Expectant management
D. Suction curettage

6. A 24-year-old G $1 \mathrm{P0}$ at 11 weeks gestation presents to your clinic with vaginal bleeding. Her vital signs arewithin normal limits. On pelvic exam her uterus appears large for her gestational date, and there is no pain or presence of adnexal masses. Serum betahC G is $265,000 \mathrm{mI} \mathrm{U} / \mathrm{ml}$. Ultrasound demonstrates hydropic changes within the placenta, presence of fetal pole but no detection of fetal heart activity. What is the most likely karyotype of the trophoblast cells on genetic analysis?
A. $69 X X Y$
B. $46 X X$
C. $46 X Y$
D. $92 X X X Y$

7. A 35-year-old G 2P1 at 8 weeks gestation presents to you with vaginal discharge and lower abdominal pain. Her temperature is $36.8^{\circ} \mathrm{C}$, blood pressure 118/ 75 , pulse 80 beats $/ \mathrm{min}$, and respiratory rate of 16 breaths/min. Pelvic exam shows uterus appropriate for gestational age, closed cervix, small amounts of blood in the introitus, and no adnexal masses or tenderness. B eta-hC G level is $12,500 \mathrm{mI} \mathrm{U} / \mathrm{ml}$. What is the next appropriate diagnostic step?
A. Chorionic villi sampling
B. Transvaginal ultrasound
C. CT scan of abdomen and pelvis
D. Complete blood count 
8. A 21-year-old G $1 \mathrm{P0}$ at 10 weeks gestation presents with severe nausea and vomiting for the past 3 weeks. The vomiting has become progressively worse and the patient feels light-headed when standing up. She denies symptoms of fever, diarrhea or abdominal pain and has no significant past medical history. Vital signs are within normal limits and fasting blood glucose is $80 \mathrm{mg} / \mathrm{dl}$. What is the best initial step in diagnosis?
A. CT of the abdomen
B. CT scan of the head
C. MRI of the pelvis
D. Beta-hCG levels

9. A 28-year-old G 3P1 presents to your clinic inquiring about future pregnancies. Her past medical history includes a dilation and curettage procedure 3 months ago for partial molar pregnancy. She has been on oral contraception since the $D \& C$ and regularly follows up for betahC G levels. What is the best recommendation for this patient regarding future pregnancies?

A. A void future pregnancies
B. A ttempt pregnancy after 3 months of contraception use

C. Can pursue pregnancy immediately after beta-hCG returns to normal levels

D. Obtain early sonogram for subsequent pregnancies

10. A 30-year-old G2P2 presents with dyspnea and chest pain for the past month. Four months ago, she had a spontaneous vaginal delivery with no complications. In the past 2 weeks, the patient noticed dark vaginal bleeding and one episode of hemoptysis. She denies symptoms of abdominal pain, vomiting, headache, weakness or skin changes. Vital signs are normal. Beta-hC G is $200,000 \mathrm{mIU} / \mathrm{ml}$ and pelvic ultrasound reveals a heterogeneous uterine mass with prominent vascular flow on Doppler. What is the next step in management for this patient?
A. Repeat beta-hCG measurement after 48 hours
B. Dilatation and curettage
C. Chest X-ray
D. CT of head

\section{ANSWERS}

1. D 2. $\begin{array}{llllllllllllllllll}\text { D } & \text { 3. } & \text { A } & \text { 4. } & \text { B } & 5 . & \text { B } & 6 . & \text { A } & 7 . & \text { B } & 8 . & \text { D } & 9 . & \text { D } & 10 . & \text { C }\end{array}$ 